\title{
CARACTERIZAÇÃO FENOLÓGICA E PRODUTIVA DAS VIDEIRAS 'CABERNET SAUVIGNON' E 'ALICANTE' (Vitis vinifera L.) PRODUZIDAS FORA DE ÉPOCA, NO NORTE DO PARANÁ 1
}

\section{BRUNO DA SILVA JUBILEU², ALESSANDRO JEFFERSON SATO², SÉRGIO RUFFO ROBERTO ${ }^{3}$}

RESUMO - Este trabalho objetivou caracterizar a fenologia e a produção das videiras 'Cabernet Sauvignon' e 'Alicante' (Vitis vinifera L.) produzidas fora de época, no norte do Paraná, para a elaboração de vinho tinto. A área experimental foi instalada em uma propriedade comercial pertencente à Vinícola Intervin ${ }^{\circledR}$, em Maringá-PR. As videiras foram conduzidas em latada sobre o 'IAC 766 Campinas'. As avaliações tiveram início a partir das podas de frutificação para a produção fora de época, durante dois anos consecutivos, realizadas no fim de janeiro de 2007 e 2008 , onde foram utilizadas 20 plantas representativas de cada variedade. Avaliou-se a duração, em dias, das principais fases fenológicas das videiras, bem como estimadas a produção por planta e a produtividade de cada variedade. A evolução de maturação das uvas foi determinada pela análise semanal do teor de sólidos solúveis totais (SST), acidez titulável (AT) e índice de maturação (SST/ AT). A duração média do ciclo da videira 'Cabernet Sauvignon' foi de 128 dias, enquanto da 'Alicante' foi de 131 dias, sendo consideradas tardias ambas as variedades para a região norte do Paraná. As estimativas da produção por planta e produtividade foram de $12,4 \mathrm{~kg}$ e 22,3 t.ha-1 para a uva 'Cabernet Sauvignon' e $11,9 \mathrm{~kg}$ e 19,8 t.ha $^{-1}$ para a 'Alicante'. Os teores médios de SST, AT e SST/AT foram de 19,2 ${ }^{\circ} \mathrm{Brix}, 1,8 \%$ de ácido tartárico e 11,6 para a uva 'Cabernet Sauvignon', e 19,1 ${ }^{\circ}$ Brix, 1,3\% de ácido tartárico e 14,1, para a 'Alicante'. Ambas as variedades apresentam elevadas produtividades e matéria-prima adequada para processamento quando produzidas fora de época no norte do Paraná.

Termos para indexação: Uva, poda, fenologia, maturação, vinho.

\section{PHENOLOGICAL AND PRODUCTIVE CHARACTERIZATION OUT OF SEASON OF 'CABERNET SAUVIGNON' AND 'ALICANTE' (Vitis vinifera L.) GRAPEVINES IN THE NORTH OF PARANÁ}

\begin{abstract}
This study aimed to characterize the phenology and the production of 'Cabernet Sauvignon' and 'Alicante' (Vitis vinifera L.) grapes produced out of season in the north of the state of Parana for red wine elaboration. The experimental area was located in a commercial property belonging to the Intervin ${ }^{\circledR}$ Winery, in Maringá, PR. The grapevines were trained in pergola system in a 4.0 x $1.5 \mathrm{~m}$ spacing, grafted on 'IAC 766 Campinas' rootstock. The evaluations started from the pruning of out of the season production, held in the end of January 2007 and 2008. For assessments, 20 representative grapevines were used of each variety. The phenology of the plants was evaluated as the duration in days, as well as it was estimated the production and productivity of each variety. The ripening development was determined by the analysis of berries chemical characteristics, such as total soluble solids (TSS), titratable acidity (TA) and maturity index (TSS/TA). It was determined that the average cycle of 'Cabernet Sauvignon' was 128 days, while the 'Alicante' was 131 days, what indicates that the cycle of both varieties are late for the north of Paraná. The production per plant and productivity estimates was $12.4 \mathrm{~kg}$ and 22.3 t.ha $^{-1}$ for 'Cabernet Sauvignon'

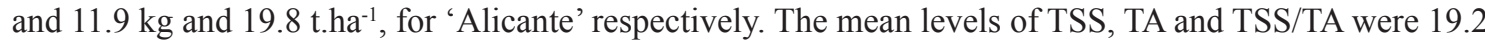
${ }^{\circ}$ Brix, $1.8 \%$ tartaric acid and 11.6 for 'Cabernet Sauvignon', and $19.1{ }^{\circ}$ Brix, $1.3 \%$ tartaric acid and 14.1 for 'Alicante' respectively. Both varieties showed high yields and suitable chemical characteristics for processing when produced out of season in the North of Parana.
\end{abstract}

Index terms: Grape, pruning, phenology, maturation, wine.

\footnotetext{
1'(Trabalho 098-09). Recebido em: 17-04-2009. Aceito para publicação em: 18-01-2010. (Parte da dissertação de Mestrado na Área de Produção Vegetal do primeiro autor, Universidade Estadual de Londrina).

${ }^{2}$ Eng. Agr., M. Sc., Universidade Estadual de Londrina, CP 6001, 86051-990, Londrina-PR. brunojubileu@yahoo.com.br, ajsato@yahoo.com.br

${ }^{3}$ Eng. Agr., Dr., Professor Associado, Departamento de Agronomia/Produção Vegetal, Universidade Estadual de Londrina, Bolsista do CNPq, CP 6001, 86051-990, Londrina-PR. sroberto@uel.br
} 


\section{INTRODUÇÃO}

O principal desafio para a obtenção de vinhos com qualidade superior no Brasil é a melhoria da qualidade da uva. Neste sentido, várias iniciativas têm sido tomadas com o propósito de desenvolver novas técnicas de produção e identificar novas regiões vitícolas, onde as condições ecológicas sejam mais favoráveis à obtenção de melhores índices de maturação e qualidade da uva (ROSIER, 2003; AMORIM et al., 2005).

A região norte do Paraná é uma área consolidada na produção de uva fina de mesa, com duas safras anuais (KISHINO ; ROBERTO, 2007). Isto é possível devido ao clima subtropical característico, com verões quentes e invernos amenos, e também pela aplicação da cianamida hidrogenada, que é fundamental para antecipar e uniformizar a brotação das gemas, logo após as podas de inverno e verão (KISHINO; CARAMORI, 2007).

Entretanto, por ocasião do aumento do volume da produção em algumas safras, tem sido observado, eventualmente, excesso de oferta do produto no mercado, acarretando em baixa remuneração da cultura. Desta forma, o cultivo de videiras destinadas à vinificação tem sido buscado como uma alternativa para a verticalização da produção de uvas na região norte do Paraná, diversificando o atual sistema baseado na produção de uvas de mesa.

Dentre as uvas tintas mais utilizadas para a vinificação, destaca-se a 'Cabernet Sauvignon' (Vitis vinifera L.), por resultar em vinhos finos e delicados. Entretanto, tem-se observado no Brasil que esta uva nem sempre atinge coloração desejada, havendo a necessidade de cortes com outros vinhos elaborados a partir de uvas tintureiras, como a 'Alicante' $(V$. vinifera $\mathrm{L}$.).

Na região norte do Paraná, as uvas europeias destinadas à vinificação, provenientes da poda de agosto e posterior colheita em janeiro, podem apresentar brotação desuniforme das gemas, e a maturação durante o verão chuvoso pode diminuir a qualidade da matéria-prima. Desta forma, deslocando-se a maturação e a colheita das uvas para o outono, quando ocorrem condições mais favoráveis, como baixa precipitação, alta amplitude térmica e temperaturas mais baixas em relação à colheita tradicional durante o verão, as chances de se obterem uvas de qualidade tecnológica superior são maiores.

Considerando esses aspectos, este trabalho teve como objetivo avaliar o comportamento fenológico e produtivo das uvas 'Cabernet Sauvignon' e 'Alicante' produzidas fora de época, destinadas à elaboração de vinhos finos na região norte do Paraná.

\section{MATERIAL E MÉTODOS}

O trabalho foi conduzido em dois vinhedos comerciais das uvas 'Cabernet Sauvignon' e 'Alicante' (Vitis vinifera L.) pertencentes à Vinícola Intervin $^{\circledR}$, localizada no município de Maringá-PR. Os indicadores climáticos médios da região são 1.600 $\mathrm{mm}$ de precipitação anual, $20,7^{\circ} \mathrm{C}$ de temperatura e $73 \%$ de umidade relativa, caracterizando-se assim como região subtropical, onde a temperatura média dos meses mais frios (junho/julho) situa-se em torno de $16,7^{\circ} \mathrm{C}$ (BORROZINO, 2004).

Foram utilizadas 20 plantas representativas de cada variedade (RIZZON ; MIÉLE, 2002), conduzidas em latada, em espaçamento de 4,0 x 1,5 m, e enxertadas em julho de 2001 sobre o porta-enxerto 'IAC 766 Campinas'. A duração dos diferentes estádios fenológicos bem como as características produtivas das videiras foram estudadas durante duas safras consecutivas, em 2007 e 2008.

A poda de formação foi realizada no final do mês de agosto, consistindo em uma poda curta, para a formação dos esporões com duas gemas. Em seguida, foi aplicada a cianamida hidrogenada a 2,5\% para a uniformização da brotação, eliminando-se toda a produção originada dos ramos brotados. A poda de frutificação, para a obtenção da produção fora de época, ocorreu no fim de janeiro, consistindo em uma poda longa, onde se deixaram entre 8 e 9 gemas por vara, e, em seguida, foi aplicada a cianamida hidrogenada a $2,5 \%$, nas três ultimas gemas, para a quebra da dormência, com o objetivo de se obter brotação uniforme das mesmas (SOUSA, 1996; AMORIM et al., 2005). O procedimento foi o mesmo para os dois anos avaliados.

Para a avaliação do comportamento fenológico das videiras, foram etiquetados 40 ramos de cada variedade. Foi avaliada nestes ramos, por meio de observações visuais, a duração em dias dos seguintes estádios, a partir da poda de frutificação: a) Gema-algodão; b) Brotação; c) Aparecimento da Inflorescência; d) Florescimento; e) Início da maturação das bagas, e f) Colheita (BAGGIOLINI,1952; BAILLOD ; BAGGIOLINI,1993).

Foi caracterizada, então, a duração em dias de cada um dos seguintes subperíodos: poda à gemaalgodão (PO-GA); poda à brotação (PO-BR); poda ao aparecimento da inflorescência (PO-AI); poda ao florescimento (PO-FL); poda ao início da maturação (PO-IM) das bagas; poda à colheita (PO-CO). A partir destes dados, foram construídos diagramas, representando em escala a duração em dias de cada uma das fases fenológicas da videira, bem como a duração de cada subperíodo (BOLIANI ; PEREIRA, 
1996).

Por ocasião da colheita, foi registrado o número de cachos por planta de cada variedade bem como determinaram-se as características físicas dos frutos por meio da coleta dos cachos de cada parcela, avaliando-se a sua massa em kg. Para a determinação do diâmetro médio das bagas, foi utilizado paquímetro digital (Starrett, Modelo 727-6/150, Alemanha), e a massa das bagas foi determinada pela pesagem de 30 bagas em balança semianalítica. Em função do número médio de cachos por planta, da massa média dos cachos e do número de plantas por hectare, foram estimadas, para cada cultivar, a produção por planta (kg.planta ${ }^{-1}$ ) e a produtividade (t.ha $\left.{ }^{-1}\right)$.

A evolução da maturação das uvas foi determinada pela análise das características químicas de suas bagas, como teor de sólidos solúveis totais (SST), acidez titulável (AT) e índice de maturação (SST/AT), as quais foram avaliadas semanalmente a partir do início da maturação dos cachos até 7 dias após a colheita, pela coleta de 300 bagas em cada amostragem (RIZZON; MIELE, 2002), divididas em 10 subamostras de 30 bagas cada, por métodos químicos (Instituto Adolfo Lutz, 1985). As análises foram realizadas no Laboratório de Frutas pertencente ao Centro de Ciências Agrárias da Universidade Estadual de Londrina-PR. O teor de SST foi determinado em refratômetro digital de bancada com compensação automática de temperatura (Modelo DR 301-95, Krüss Optronic, Alemanha), pelo esmagamento das amostras e posterior filtragem em algodão, e o resultado, expresso em ${ }^{\circ}$ Brix. A determinação da AT foi realizada por titulação do suco com solução padronizada de $\mathrm{NaOH} 0,1 \mathrm{~N}$ em titulador potenciométrico digital (Modelo Tritoline Easy, Schott Geräte, Alemanha) ajustado a $\mathrm{pH}=8,2$ como ponto final de titulação, e o resultado, expresso em porcentagem de ácido tartárico. A partir dos dados obtidos, obteve-se, pelas médias, o comportamento das variáveis analisadas (SST, AT e SST/AT das bagas) em função do tempo (RIZZON; MIELE, 2002).

Os dados climáticos da região, nos anos de 2007 e 2008, como temperaturas médias mensais e precipitação total mensal, foram obtidos junto à Universidade Estadual de Maringá.

\section{RESULTADOS E DISCUSSÃO}

\section{videiras}

Fenologia e características produtivas das

A duração do período $\mathrm{PO}-\mathrm{CO}$ da uva 'Cabernet Sauvignon' produzida fora de época, no norte do Paraná, foi de 132 dias na safra de 2007, enquanto a duração dos subperíodos PO-GA, POBR, PO-AI, PO-FL e PO-IM foi de 9; 13; 32; 38 e 80 dias, respectivamente (Figura 1).

Na safra de 2008, o ciclo foi semelhante, porém um pouco mais curto, totalizando 125 dias, sendo que a duração dos subperíodos PO-GA, POBR, PO-AI, PO-FL e PO-IM foi de 8; 14; 33; 39 e 89 dias, respectivamente (Figura 1), e considerando as duas safras fora de época avaliadas, a duração média do período PO-CO da videira 'Cabernet Sauvignon' foi de 128 dias.

Escassas são as informações sobre as características fenológicas e produtivas de videiras cuja produção destinada à vinificação é obtida fora de época, visando à obtenção vinhos de melhor qualidade no norte do Paraná, sendo que as disponíveis se referem, em sua maioria, à safra proveniente da poda de inverno, ou seja, obtida no verão. Na Serra Gaúcha, a uva 'Cabernet Sauvignon' é considerada de brotação e maturação tardias, apresentando ciclo médio (brotação à colheita) de 168 dias (KUHN et al., 1996). Na região de Bourdeaux, França, o ciclo da 'Cabernet Sauvignon' dura, em média, 193 dias (JONES; DAVIS, 2000), enquanto na Patagônia, na Argentina, o ciclo é maior (213 dias) (LLORENTE, 2007), uma vez que esta região apresenta temperaturas mais baixas, prolongando o ciclo das videiras. Na região de Talca, no Chile, a uva 'Cabernet Sauvignon' apresenta ciclo de 122 dias (IPPOLITO, 2004), sendo ainda mais curto que os descritos anteriormente.

Na região norte do Paraná, Roberto et al. (2005) observaram, em safra proveniente da poda de inverno, que o ciclo da uva 'Cabernet Sauvignon' dura, em média, 126 dias, sendo que a duração dos subperíodos PO-GA, PO-BR, PO-AI, PO-FL e POIM foi de 13; 18; 21; 43 e 93 dias, respectivamente, ou seja, a produção em época normal desta videira apresenta ciclo um pouco mais curto quando comparada ao ciclo de produção fora de época, uma vez que a maturação desta última ocorre em períodos de temperaturas mais baixas. Esta é uma vantagem para a região, pois mesmo em condições de temperaturas mais amenas no inverno (Figura 2), o ciclo da videira não é demasiado longo.

O conhecimento da duração das fases fenológicas é uma exigência da viticultura moderna, uma vez que possibilita a racionalização e a otimização das práticas culturais, que são indispensáveis para o cultivo da videira (MANDELLI et al., 2004), sobretudo quando se obtém produção fora de época. Desta forma, é possível programar datas de poda, quebra de dormência, aplicação de defensivos, colheita e também otimizar o emprego da mão de 
obra nas diversas fases do ciclo, reduzindo os tratos fitossanitários, resultando em economia de insumos (MURAKAMI et al., 2002). Além disso, em função do histórico do regime de chuvas de uma região subtropical, pode ser mais bem programada a poda de frutificação e quebra de dormência no verão para a obtenção da produção fora de época, em que a maturação dos cachos ocorre em condições climáticas mais favoráveis, uma vez que, neste período, é importante que não haja excesso de umidade nos cachos, evitando-se assim a ocorrência de podridões fúngicas que prejudicam o processo fermentativo da vinificação.

Em relação às características produtivas, a 'Cabernet Sauvignon' apresentou diâmetro e massa das bagas, nas safras de 2007 e 2008, médias de $11,9 \mathrm{~mm}$ e $1,0 \mathrm{~g}$, respectivamente (Tabela 1). Santos et al. (2007) constataram que o diâmetro e a massa das bagas desta videira, em safra normal na mesma região, são de $12,0 \mathrm{~mm}$ e $1,2 \mathrm{~g}$, respectivamente, muito semelhante ao observado neste trabalho. Para esta mesma uva, Rizzon e Miele (2002) observaram diâmetro e massa iguais a 14,0mm e 1,4g, respectivamente, na Serra Gaúcha. Jones e Davis (2000) descrevem que a massa média das bagas na região de Bordeaux, França, é de 1,2g, enquanto Lima et al. (2003) observaram diâmetro de 12,0mm no Vale do Rio São Francisco. Verifica-se que as bagas produzidas fora de época, neste trabalho, são semelhantes às observadas em outras regiões do Brasil e do mundo.

$\mathrm{O}$ número de cachos por planta, a massa dos cachos, as estimativas de produção por planta e a produtividade da uva 'Cabernet Sauvignon', nas safras de 2007 e 2008, foram de 82,6 e 75,6; 170 e $130 \mathrm{~g} ; 13,9$ e 9,8 kg.planta ${ }^{-1}$; e 23,2 e 16,3 t.ha ${ }^{-1}$, respectivamente, resultando em médias de 79,1 ; 150g; 11,8 kg.planta ${ }^{-1}$ e 19,7 t.ha ${ }^{-1}$, respectivamente (Tabela 1). No norte do Paraná, Santos et al. (2007) determinaram, em safra obtida a partir de poda de inverno, que esta videira apresenta, em média, 78,7 cachos por planta, com massa média de $0,12 \mathrm{~kg}$, e produção estimada de $9,5 \mathrm{~kg}$. planta ${ }^{-1}$ e produtividade de 15,9 t.ha' ${ }^{-1}$.

Rizzon e Miele (2002) apontam que a massa dos cachos para essa variedade é de $0,14 \mathrm{~kg}$, sendo consideravelmente superior ao constatado por Lima et al. (2003) no Vale do Rio São Francisco $(0,08 \mathrm{~kg})$, porém inferior à média das duas safras fora de época avaliadas neste trabalho. Na região da Campanha Gaúcha, Brunetto et al. (2007) observaram produtividade de 15,5 t.ha ${ }^{-1}$ e produção de 13,1 kg.planta-1, enquanto para as condições da Serra Gaúcha, Giovannini (2003) obteve produtividade de 11,4 t.ha' ${ }^{-1}$. Souza et al. (2002) constataram que a produtividade desta videira, em Minas Gerais, é de 11,7 t.ha $^{-1}$ e a produção de $4,7 \mathrm{~kg}$.planta ${ }^{-1}$, todas cultivadas em espaldeira.

Para a uva 'Alicante' produzida fora de época no norte do Paraná, a duração do período PO-CO foi de 133 dias na safra 2007 e a duração dos subperíodos PO-GA, PO-BR, PO-AI, PO-FL e PO-IM foi de 7; 11; 35; 41 e 86 dias, respectivamente (Figura 3).

$\mathrm{Na}$ safra 2008, a duração do período PO-CO foi semelhante à anterior, porém um pouco mais curta, totalizando 130 dias, sendo que a duração dos subperíodos PO-GA, PO-BR, PO-AI, PO-FL e PO-IM foi de $6 ; 10 ; 29 ; 37$ e 87 dias, respectivamente (Figura 3). Considerando as duas safras fora de época avaliadas, a duração do período PO-CO foi em média 131 dias.

As características de produção da uva 'Alicante', como diâmetro e massa das bagas, número de cachos por planta, massa dos cachos, e as estimativas de produção por planta e produtividade, nas safras 2007 e 2008 , foram de 17,8 e $15,0 \mathrm{~mm}$ e 1,9 e 2,2g, 37,7 e 35,$4 ; 340$ e $320 \mathrm{~g} ; 12,8$ e 11,0 kg.planta ${ }^{-1}$; e 21,3 e 18,4 t.ha ${ }^{-1}$, respectivamente, o que resulta em médias de 16,4mm; 2,05g; 36,55; 330g; 11,9 kg.planta ${ }^{-1} \mathrm{e}$ 19,82 t.ha-1 ${ }^{-1}$ respectivamente (Tabela 1 ). Não foram encontradas informações sobre as características fenológicas e produtivas da uva 'Alicante' cultivada no Brasil. Entretanto, pode-se considerar que esta uva produzida fora de época, no norte do Paraná, apresenta ciclo tardio, próximo ao observado para a uva 'Cabernet Sauvignon'.

Neste trabalho, observou-se que o ciclo das videiras produzidas fora de época varia de um ano para outro, pois em regiões subtropicais as condições climáticas são irregulares, exercendo grande influência no desenvolvimento vegetativo das videiras. Conforme pode ser observado na Figura 2, ocorreu maior precipitação no mês de junho de 2008 em relação ao mesmo mês em 2007, justamente no período da maturação das uvas, acarretando em antecipação da colheita para garantir que as características químicas das bagas fossem satisfatórias para sua vinificação. Entretanto, ressalta-se que, mesmo assim, a colheita nas duas safras avaliadas ocorreu em períodos em que a precipitação foi inferior quando comparada à colheita das uvas proveniente da poda de inverno.

A produção fora de época das videiras ' $C a b e r-$ net Sauvignon' e 'Alicante' resultou em estimativas de produção e de produtividade com elevado potencial para a região norte do Paraná. Além disso, os cachos foram colhidos com excelentes características sanitárias, livres de podridões, justamente pelo deslocamento da safra para condições onde as precipitações são menores, as temperaturas são amenas e a amplitude térmica é maior, proporcionando uma adequada 
coloração das bagas. Resultados semelhantes foram observados por Amorim et al. (2005) para a uva 'Syrah' produzida fora de época, em Minas Gerais.

As médias de produtividade das videiras observadas neste trabalho podem ser consideradas altas para a obtenção de vinhos de qualidade, pois em outras regiões do Brasil e do mundo as médias encontradas são menores, não ultrapassando 12 t.ha ${ }^{-1}$ (MURISIER ; ZIEGLER, 1991; SOUZA et al., 2002; GIOVANINNI, 2003). Desta forma, para a elaboração de vinhos de qualidade superior, no norte do Paraná, a partir destas variedades, seria interessante o raleio dos cachos para limitar a produção, conforme relatado por Palliotti e Cartechini (2000) e Silva et al. (2008).

\section{Evolução da maturação das uvas}

Observa-se que a evolução do teor de SST para a uva 'Cabernet Sauvignon', produzida fora de época no norte do Paraná, foi progressiva desde o início da maturação (Figura 1), atingindo na colheita 19,4 e $18,9^{\circ}$ Brix, nas safras de 2007 e 2008 , respectivamente, o que resultou em média de $19,2^{\circ}$ Brix (Tabela 2).

O início da maturação ocorreu, em média, aos 46 dias após o florescimento, quando houve um ganho acelerado de SST nas bagas a partir desse período. Isto se deve ao acúmulo de açúcares por meio da fotossíntese das folhas que migram pelo floema e chegam em forma de sacarose nas bagas. Posteriormente, a sacarose é hidrolisada e transformada em glicose e frutose que são os açúcares predominantes nas bagas, por duas invertases, uma na membrana plasmática e outra no vacúolo das células (BLOUIN; GUIMBERTEAU, 2004).

No Brasil, raras são as informações sobre a maturação da uva 'Cabernet Sauvignon' produzida fora de época, sendo os resultados disponíveis essencialmente de safras provenientes da poda de inverno e obtidas no verão, os quais variam muito em função da região e das técnicas de cultivo empregadas. Rizzon e Miele (2002) descrevem que a uva 'Cabernet Sauvignon', na Serra Gaúcha, apresenta teor médio de $18,1^{\circ}$ Brix na colheita, enquanto na região do Vale do Rio São Francisco, Lira et al. (2003) relataram que, dependendo da safra, esta uva pode atingir $23,5^{\circ}$ Brix. Este valor é próximo ao relatado por Nuzzo e Matthews (2006) na região do Napa Valley, na Califórnia, os quais obtiveram teor de $24^{\circ}$ Brix para esta videira. Em Toledo, região oeste do Paraná, Detoni et al. (2007) observaram para a uva 'Cabernet Sauvignon' teor de $17,3^{\circ}$ Brix na colheita quando cultivada sob cobertura plástica.

Em relação aos dados apresentados, o teor médio de SST da uva 'Cabernet Sauvignon' produzida fora de época, no norte do Paraná, pode ser consi- derado adequado para a elaboração de vinhos, sem que o mosto necessite de "chapitalização" durante a vinificação, pois o teor observado é suficiente para elaboração de vinhos com graduação alcoólica entre 10 e $13^{\circ} \mathrm{GL}$, como determina a legislação brasileira, uma vez que, para a formação de cada $1^{\circ} \mathrm{GL}$ de álcool, é necessário 1,8 ${ }^{\circ}$ Brix do mosto (GUERRA; ZANUS, 2003).

A evolução da AT do mosto durante a fase de maturação foi decrescente e inversa em relação à evolução do teor de SST (Figura 4). Nas safras de 2007 e 2008, o mosto da 'Cabernet Sauvignon', durante a colheita, apresentou 1,3 e 2,4\% de ácido tartárico, respectivamente, com média de 1,8\% (Tabela 2), a qual é maior que as observadas por outros autores, como no Vale do São Francisco, em que Lira et al. (2003) constataram baixa acidez desta uva ( $0,4 \%$ de ácido tartárico). Na Serra Gaúcha, Rizzon e Miele (2002) relataram que a acidez desta variedade é, em média, 0,85\%, enquanto Santos et al. (2007) constataram que, em Maringá-PR, a uva 'Cabernet Sauvignon' atinge $0,8 \%$ de ácido tartárico na safra proveniente da poda de inverno.

A evolução decrescente de AT do mosto deve-se a diversos fatores, os quais: diluição dos ácidos orgânicos por aumento do volume da baga; ativação da quebra de ácidos orgânicos e inibição de sínteses e transformação dos ácidos orgânicos em açúcar (MULLINS et al., 1992). Entretanto, a AT observada neste trabalho é considerada adequada, pois durante a vinificação em tinto da uva 'Cabernet Sauvignon' ocorre considerável redução da sua acidez, devido principalmente à salificação e à precipitação do ácido tartárico e à fermentação malolática (RIZZON et al., 1998).

Em relação ao índice de maturação do mosto, observa-se, nas duas safras estudadas (Figura 4), que sua evolução foi crescente devido ao aumento no teor de SST e à diminuição de AT (15,3 em 2007 e 8,1 em 2008), resultando na média de 11,6 (Tabela 2).

Esses valores são inferiores aos relatados na Serra Gaúcha $(20,6)$ por Rizzon e Miele (2002) e menores ainda em comparação com a média obtida no Vale São Francisco $(58,6)$ por Lira et al. (2003). Estas diferenças entre as regiões podem variar de acordo com a forma de cultivo e as condições climáticas, o que reflete em diferenças no acúmulo de SST e redução de AT no mosto (SANTOS et al., 2005).

Ressalta-se que a utilização do índice de maturação deve ser feita com cuidado, pois nem sempre um aumento de açúcar corresponde a uma diminuição da acidez titulável e não é indicada para comparar mostos de diferentes cultivares (RIZZON; MIÉLE, 2003). Este índice serve, 
portanto, como referência de uma safra considerada ótima sob o ponto de vista enológico (BLOUIN; GUIMBERTEAU, 2004).

O decréscimo, tanto dos teores de SST como no índice de maturação, e o aumento na acidez, na safra de 2008, devem-se às variações climáticas em regiões subtropicais, principalmente em relação à temperatura do ar e à chuva. Segundo RibéreauGayon et al. (1986), o teor de ácido tartárico das bagas tem grande relação com a temperatura e, sobretudo, com a circulação de água na planta. Períodos quentes e secos contribuem para a redução do teor de ácido tartárico da uva. Por outro lado, precipitações contínuas por alguns dias favorecem o aumento do ácido tartárico, ocorrendo o inverso com o teor de SST. Na safra de 2008, observaram-se precipitações durante a maturação e colheita (junho), porém em 2007 as precipitações neste período foram menores (Figura 2).

Para a uva 'Alicante', a evolução dos SST do mosto foi também progressiva desde o início da maturação (Figura 5). A partir de 63 dias após o florescimento, até próximo da colheita, incrementos semanais mais importantes foram detectados, atingindo 21,7 e $16,4^{\circ}$ Brix nas safras de 2007 e 2008, respectivamente, com média de $19,1^{\circ}$ Brix (Tabela 2). Na região do Vale do Rio São Francisco, Wyler et al. (2007) relataram que a mesma uva pode atingir $21,7^{\circ}$ Brix, semelhante ao encontrado na primeira safra fora de época avaliada neste trabalho.

Em relação à evolução da AT do mosto, observou-se declínio desde o começo das avaliações (Figura 5), chegando a 1,3\% de ácido tartárico em ambas as colheitas (Tabela 2). Para esta uva, observou-se teor de $0,65 \%$ no Vale do São Francisco (WYLER et al., 2007), valor menor que o encontrado nas duas safras fora de época neste trabalho.

Os índices de maturação observados foram de 16,9 e 11,3 , com média de 14,1 (Tabela 2 ), havendo incremento a partir do $48^{\circ}$ dia após o florescimento, devido ao aumento do teor de SST e concomitante diminuição do teor de AT (Figura 5). Para as condições do Vale do São Francisco, o índice de maturação desta uva foi de 33,4 (WYLER et al., 2007), superior ao encontrado neste trabalho.

Apesar da queda dos índices, tanto do teor de SST quanto do índice de maturação na safra de 2008 , os resultados apresentados neste trabalho reforçam as afirmações de Gonçalves et al. (2002), que relataram que os atributos de qualidade, tais como SST e AT, apresentam fundamental importância no monitoramento do ponto de colheita dos frutos de videira, possibilitando melhor controle de qualidade da matéria-prima a ser utilizada na elaboração de vinhos. Além disso, os cachos deste trabalho foram colhidos com excelentes características sanitárias, livres de podridões, justamente pelo deslocamento da safra para condições onde as precipitações são menores, as temperaturas são amenas e a amplitude térmica é maior, conforme também observado por Amorim et al. (2005). Ressalta-se, entretanto, que outras características químicas das bagas são também importantes para a obtenção de vinhos de qualidade, como polifenóis, taninos, antocianinas e complexos aromáticos (GUERRA ; ZANUS, 2003)

Pelos resultados obtidos neste trabalho, devido à duração dos ciclos das variedades estudadas, é possível a obtenção de produção fora de época no outono, onde a maturação das uvas ocorre em condições climáticas mais favoráveis, livres de podridões, resultando matéria-prima adequada para a obtenção de vinhos tintos

TABELA 1 - Características produtivas das videiras 'Cabernet Sauvignon' e 'Alicante' (Vitis vinifera L.) produzidas fora de época no norte do Paraná. Maringá, 2009.

\begin{tabular}{ccccccc}
\hline Variedade & \multicolumn{3}{c}{ 'Cabernet Sauvignon' } & \multicolumn{3}{c}{ 'Alicante' } \\
\cline { 2 - 7 } Características produtivas & $\mathbf{2 0 0 7}$ & $\mathbf{2 0 0 8}$ & Média & $\mathbf{2 0 0 7}$ & $\mathbf{2 0 0 8}$ & Média \\
\hline Diâmetro médio das bagas (mm) & $12,0 \pm 0,6$ & $11,7 \pm 0,8$ & $11,9 \pm 0,2$ & $17,8 \pm 1,2$ & $15,0 \pm 1,4$ & $16,4 \pm 2,0$ \\
Massa média das bagas (g) & $1,0 \pm 0,09$ & $1,0 \pm 0,09$ & $1,0 \pm 0,0$ & $1,9 \pm 0,1$ & $2,2 \pm 0,2$ & $2,05 \pm 0,2$ \\
Número médio de cachos por & $82,6 \pm 3,8$ & $75,6 \pm 4,6$ & $79,1 \pm 4,9$ & $37,7 \pm 3,9$ & $35,4 \pm 4,2$ & $36,6 \pm 1,6$ \\
planta & $170 \pm 10$ & $130 \pm 10$ & $150 \pm 20$ & $340 \pm 90$ & $320 \pm 90$ & $330 \pm 10$ \\
Massa média dos cachos (g) & 13,9 & 9,8 & 11,8 & 12,8 & 11,0 & 11,9 \\
${\left.\text { Produçãopor planta a/(kg.planta }{ }^{-1}\right)}^{\text {Produtividade }}{ }^{/ b}\left(\mathrm{t}_{\text {.ha }}{ }^{-1}\right)$ & 23,2 & 16,3 & 19,7 & 21,3 & 18,4 & 19,8 \\
\hline
\end{tabular}

${ }^{a}$ : Estimativa em função do número médio de cachos por planta e da massa média dos cachos.

${ }^{\mathrm{b}}$ : Estimativa em função da produção média por planta e do número de plantas por hectare. 
TABELA 2-Características químicas do mosto das bagas das videiras 'Cabernet Sauvignon' e 'Alicante' (Vitis vinifera L.) produzidas fora de época no norte do Paraná. Maringá, 2009.

\begin{tabular}{|c|c|c|c|c|c|c|}
\hline \multirow{2}{*}{$\begin{array}{c}\text { Características } \\
\text { químicas }\end{array}$} & \multicolumn{3}{|c|}{ 'Cabernet Sauvignon' } & \multicolumn{3}{|c|}{ 'Alicante' } \\
\hline & 2007 & 2008 & Média & 2007 & 2008 & Média \\
\hline $\mathrm{SST}^{\mathrm{a} /}$ & $19,4 \pm 0,14$ & $18,9 \pm 2,6$ & $19,2 \pm 0,4$ & $21,7 \pm 0,4$ & $16,4 \pm 0,3$ & $19,1 \pm 3,7$ \\
\hline $\mathrm{AT}^{\mathrm{b} /}$ & $1,3 \pm 0,02$ & $2,4 \pm 0,3$ & $1,8 \pm 0,7$ & $1,3 \pm 0,08$ & $1,3 \pm 0,09$ & $1,3 \pm 0,0$ \\
\hline $\mathrm{SST} / \mathrm{AT}^{\mathrm{c}}$ & $15,1 \pm 0,2$ & $8,1 \pm 2,3$ & $11,6 \pm 4,9$ & $16,9 \pm 1,3$ & $11,3 \pm 2,1$ & $14,1 \pm 3,9$ \\
\hline
\end{tabular}

${ }^{a}$ : Sólidos solúveis totais.

b/: Acidez titulável.

c/: Índice de maturação.
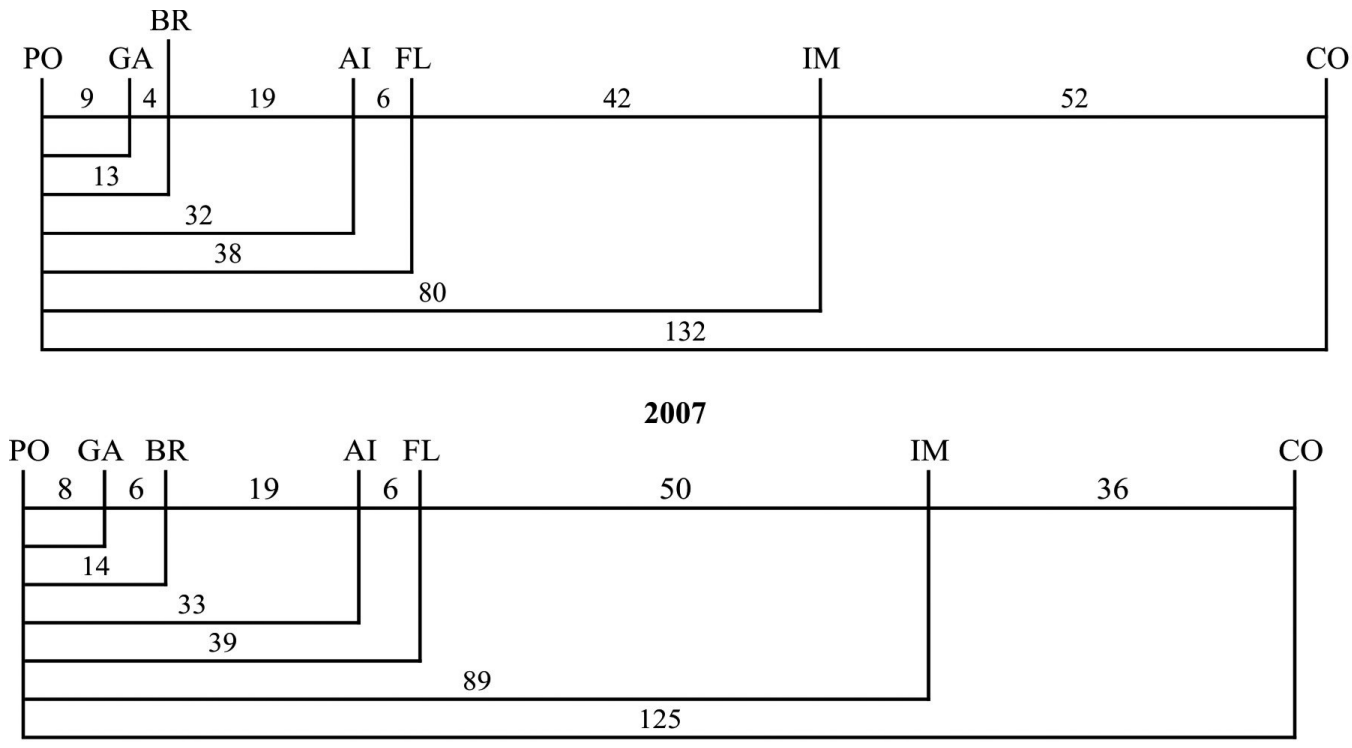

2008

FIGURA 1- Duração em dias dos estádios fenológicos da videira 'Cabernet Sauvignon' produzida fora de época no norte do Paraná, nas safras de 2007 e 2008. (PO): Poda; (GA): Gema-algodão; (BR): Brotação; (AI): Aparecimento da Inflorescência; (FL): Florescimento; (IM): Início da Maturação; (CO): Colheita. Maringá, 2009. 

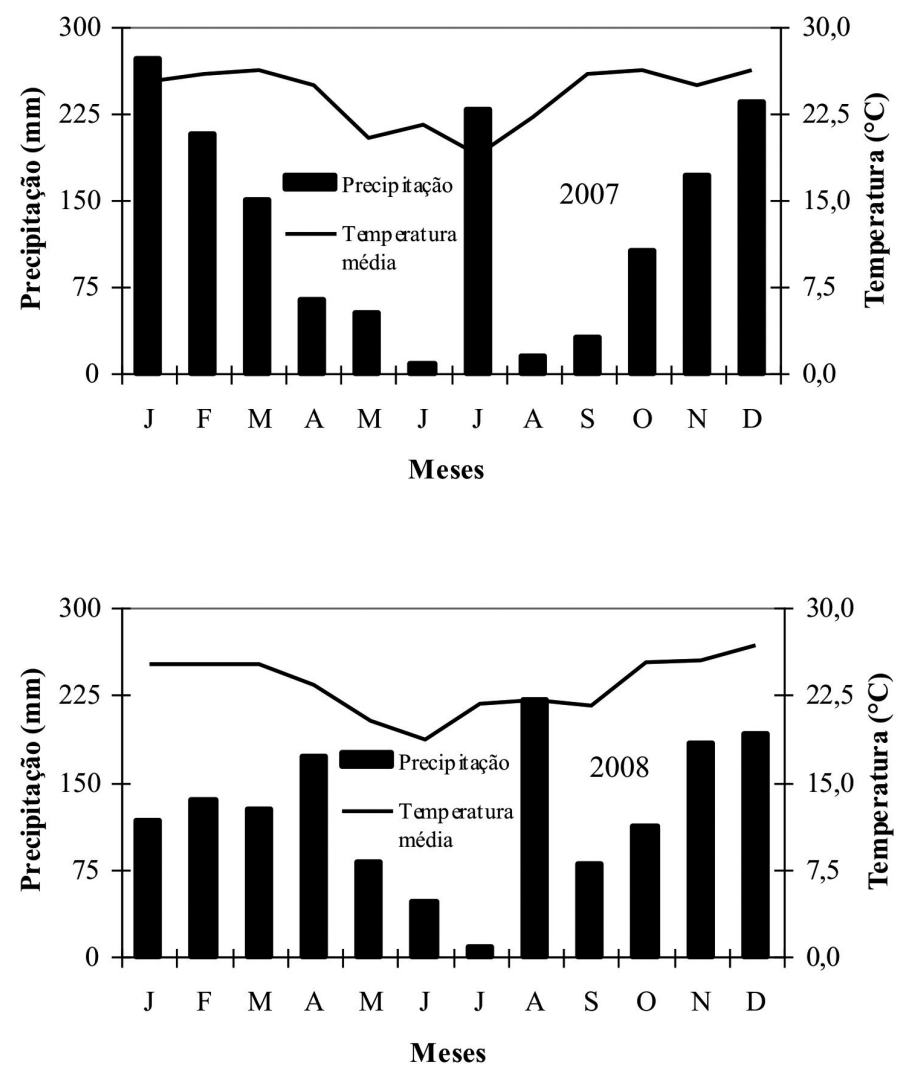

FIGURA 2 - Precipitação pluviométrica e temperatura média total mensal durante os anos de 2007 e 2008 , no norte do Paraná. Fonte: Universidade Estadual de Maringá. Maringá, 2009.
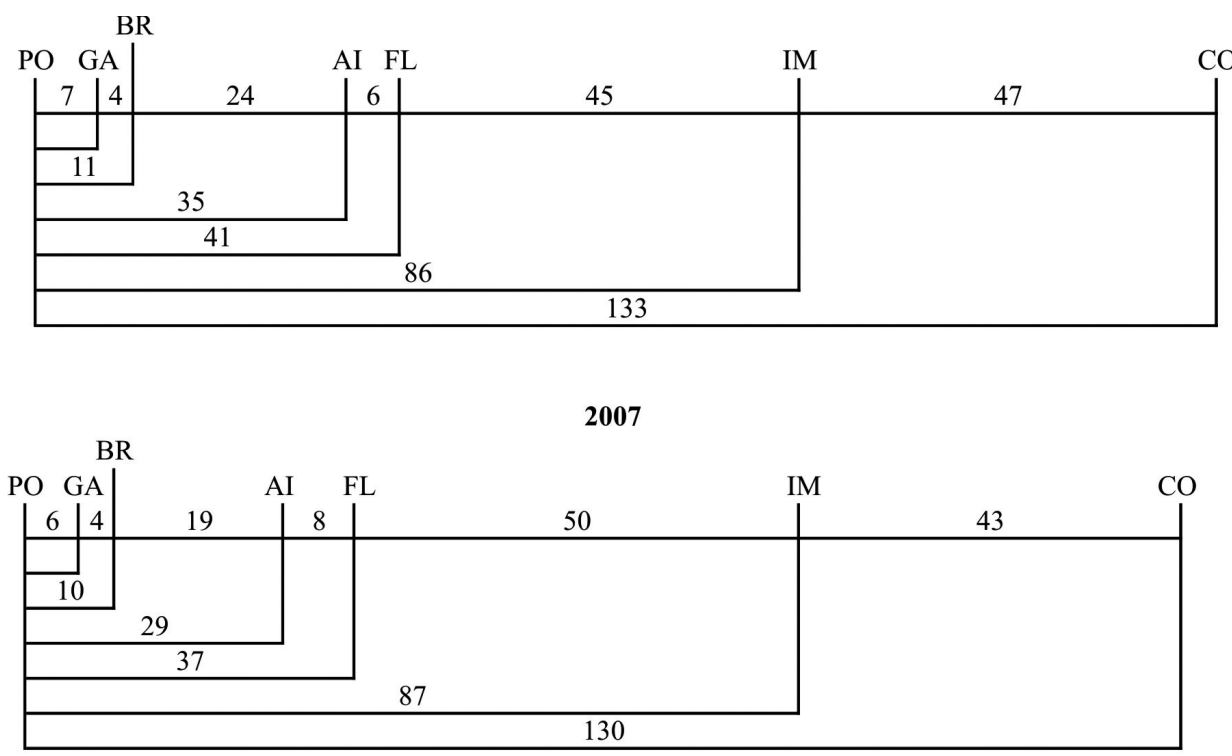

2008

FIGURA 3 - Duração em dias dos estádios fenológicos da videira 'Alicante' produzida fora de época no norte do Paraná, nas safras de 2007 e 2008. (PO): Poda; (GA): Gema-algodão; (BR): Brotação; (AI): Aparecimento da Inflorescência; (FL): Florescimento; (IM): Início da Maturação; (CO): Colheita. Maringá, 2009. 

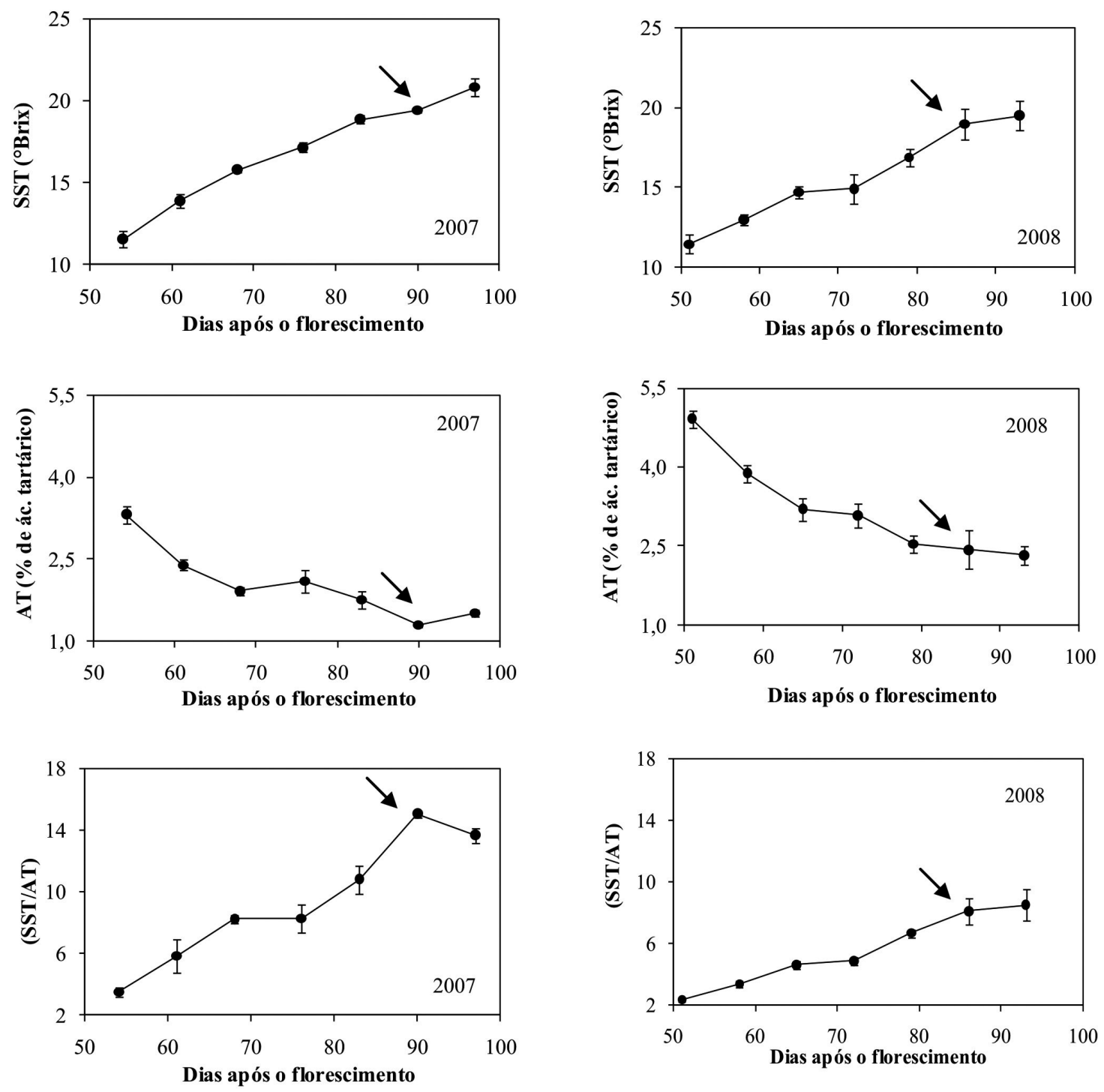

FIGURA 4 - Evolução dos sólidos solúveis totais (SST), acidez titulável (AT) e índice de maturação (SST/ AT), do mosto da uva 'Cabernet Sauvignon' produzida fora de época no norte do Paraná, nas safras de 2007 e 2008. Maringá, 2009. Obs: Setas indicam o momento da colheita. 

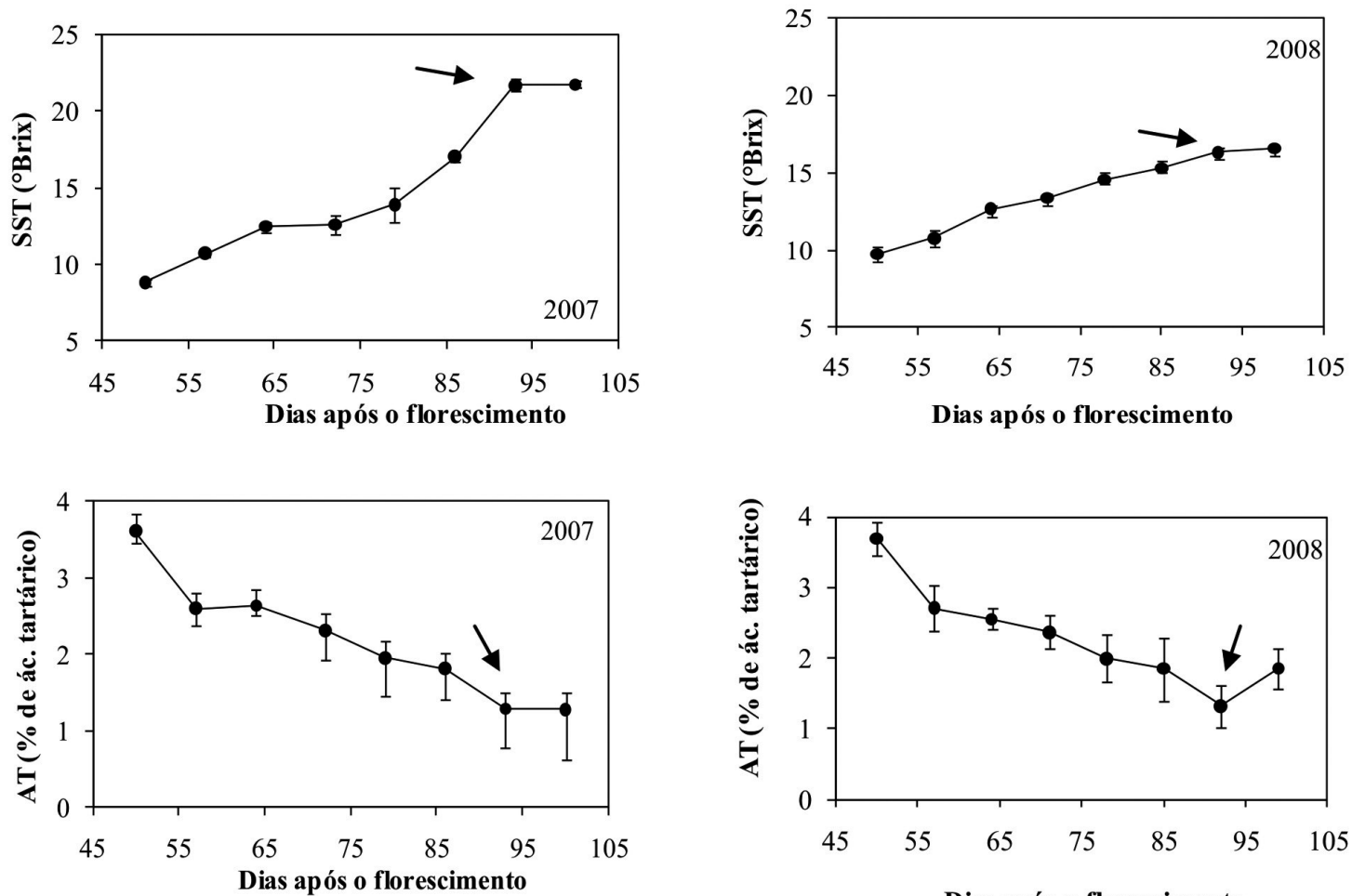

Dias após o florescimento
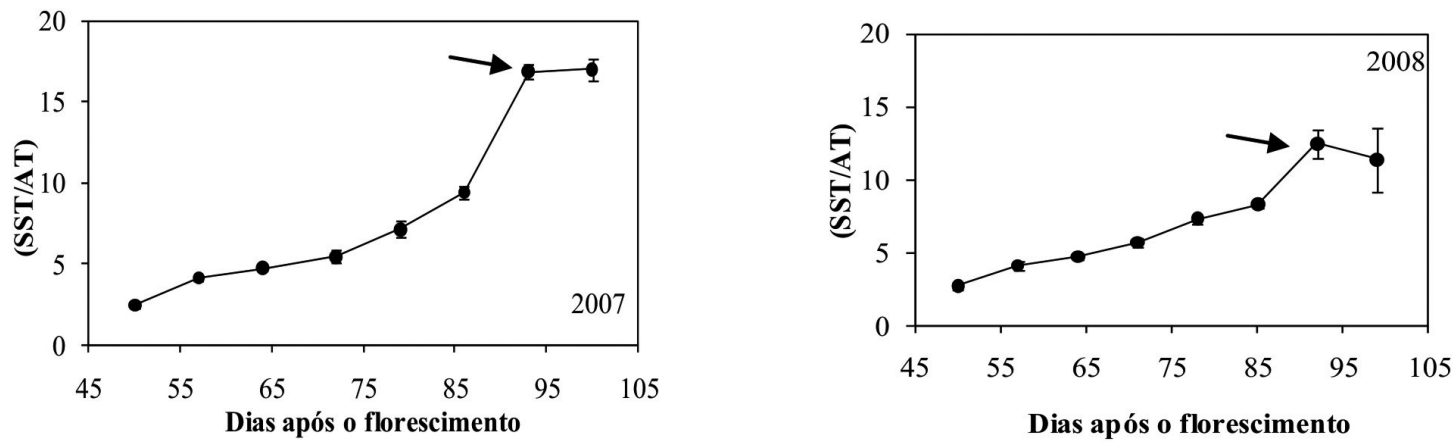

FIGURA 5 - Evolução dos sólidos solúveis totais (SST), acidez titulável (AT) e índice de maturação (SST/ AT), do mosto da uva 'Alicante' produzida fora de época no norte do Paraná, nas safras de 2007 e 2008. Maringá, 2009. Obs: Setas indicam o momento da colheita. 


\section{CONCLUSÕES}

As uvas 'Cabernet Sauvignon' e 'Alicante', cultivadas para a produção fora de época no norte do Paraná, apresentam ciclo tardio e elevada produtividade, e a maturação dos cachos ocorre em condições climáticas favoráveis, resultando em matéria-prima adequada para a elaboração de vinhos tintos.

\section{REFERÊNCIAS}

AMORIM, D.A.; FAVERO, A.C.; REGINA, M.A. Produção extemporânea da videira, cultivar Syrah, nas condições do sul de Minas Gerais. Revista Brasileira de Fruticultura, Jaboticabal, v.27, n.2, p. 327-331, 2005.

BAGGIOLINI, M. Lês stades repères dans lê developpement anual de la vigne. Revue Romande: Revue mensuelle d agriculture, de viticulture et $\mathrm{d}$ arboriculture, Lausanne, v.8, p.4-5, 1952.

BAILLOD, M.; BAGGIOLINI, M. Lês stades repères de la vigne. Revue Suisse Viticulture Horticulture, Croft, v. 25, n.1, p.7-9, 1993.

BLOUIN, J.; GUIMBERTEAU, G. Maduración y madurez de la uva. Madrid: Ediciones MundiPrensa, 2004.

BOLIANI, A.C.; PEREIRA, F.M. Avaliação fenológica de videiras (Vitis vinifera $\mathrm{L}$.) cultivares Itália e Rubi, submetidas à poda de renovação na região oeste do Estado de São Paulo. Revista Brasileira de Fruticultura, Jaboticabal, v.18, n.2, p.193-200, 1996.

BORROZINO, E. Média dos dados climáticos da região norte do Paraná. Londrina: IAPAR, 2004. Disponível em: <www.iapar.br>. Acesso em: 15 jan. 2008.

BRUNETTO, G.; CERETTA, C. A.; KAMINSKI, J.; MELLO G.W.B.; LOURENZI, C.R.; FURLANETTO, V.; MORAES, A. Aplicação de nitrogênio em videiras na Campanha Gaúcha: produtividade e características químicas do mosto da uva. Ciência Rural, Santa Maria, v.37, n.2, p. 389-393, 2007.

DETONI, A.M.; CLEMENTE, E.; FORNARI, C. Produtividade e qualidade da uva 'Cabernet Sauvignon' produzida sob cobertura de plástico em cultivo orgânico. Revista Brasileira de Fruticultura, Jaboticabal, v.29, n.3, p.530-534, 2007.
GIOVANNINI, E. Avaliação da adaptabilidade de cvs. para vinho fino na campanha e na serra gaúcha através do teor de açúcar e da produtividade. In: CONGRESSO BRASILEIRO DE VITICULTURA E ENOLOGIA, 10., 2003, Bento Gonçalves. Anais... Bento Gonçalves: Embrapa Uva e Vinho, 2003. p. 184.

GONÇALVES, C.A.A.; LIMA, L.C.O.; CHALFUN, N.N.J.; REGINA, M.A.; ALVARENGA, A.A.; SOUZA, M.T. Fenologia e qualidade do mosto de videiras 'Folha de Figo' sobre diferentes porta-enxertos, em Caldas, sul de Minas Gerais. Ciência e Agrotecnologia, Lavras, v.26, n.6, p.1178-1184, 2002.

GUERRA, C.C.; ZANUS, M.C. Uvas viníferas para processamento em região de clima temperado, 2003. Disponível em: <http://www.cnpuv.embrapa. br/publica/sprod/UvasViniferasRegioesClimaTemperado/colheita.htm>. Acesso em: 11 mar.2008.

INSTITUTO ADOLFO LUTZ. Normas analíticas do Instituto Adolfo Lutz: métodos químicos e físicos para análise dos alimentos. 3. ed. São Paulo: Instituto Adolfo Lutz, 1985. v. 1.

IPPOLITO, O.P. Estudios fenológicos en los cvs. Chardonnay, Sauvignon gris, Cabernet Sauvignon y Merlot. 2004. Monografia. (Graduação em Engenharia e Agronomia Florestal) - Facultad de Agronomía e Ingeniería Forestal. Pontificia Universidad Católica de Chile, Santiago, 2004. Disponível em: <http://www.puc.cl/agronomia/2 alumnos/ ProyectosTitulos/pdf/FruticulturaEnologia/OrnellaPasteneI.pdf $>$. Acesso: 15 jun. 2008.

JONES, G.V.; DAVIS, R.E. Climate influences on grapevine phenology, grape composition, and wine production and quality for Bourdeaux, France. American Journal of Enology and Viticulture, Davis, v.51, n.3, p.249-261, 2000.

KISHINO A.Y.; CARAMORI, P.H. Fatores climáticos e o desenvolvimento da videira. In: KISHINO A. Y. et al. Viticultura tropical: o sistema de produção do Paraná. Londrina: IAPAR, 2007. p.59-86.

KISHINO A.Y;; ROBERTO S.R. Tratos culturais. In: KISHINO, A. Y. et al. Viticultura tropical: o sistema de produção do Paraná. Londrina: IAPAR, 2007. p.171-202

KUHN, G.B.; LOVATEL, J.L.; PREZOTTO, O.P.; RIVALDO, O. F.; MANDELI, F.; SÔNEGO, O. R. $O$ cultivo da videira: informações básicas. 2.ed. Bento Gonçalves: EMBRAPA-CNPUV, 1996. 60p. (Circular Técnica, 10). 
LIMA, M.A.C.; LEÃO, P.C.S.; RIBEIRO, A.P.L.; TRINDADE, D.C.G. Maturação de cultivares de uva nas condições do submédio São Francisco. In: CONGRESSO BRASILEIRO DE VITICULTURA E ENOLOGIA, 10., 2003, Bento Gonçalves. Anais... Bento Gonçalves: Embrapa Uva e Vinho, 2003. p. 196.

LIRA, M.M.P.; ARNAULD, A.A.; GUERRA, C.C.; LIMA, M.V.D.O.; XAVIER, P.R. Características físico-químicas da uva das cultivares Cabernet Sauvignon e Viognier cultivadas na Vale do Submédio São Francisco. In: CONGRESSO BRASILEIRO DE VITICULTURA E ENOLOGIA, 10., 2003, Bento Gonçalves. Anais... Bento Gonçalves: Embrapa Uva e Vinho, 2003. p.194.

LLORENTE, A. Fenologia y madurez de uva para vinificar. 2007. Disponível em: <http://www.inta. gov.ar/ALTOVALLE/info/biblo/rompecabezas/pdfs/ rompe39 llorente.pdf>. Acesso em: 7 jun. 2007.

MANDELLI, F.; TONIETTO, J.; CAMARGO, U.A.; CZERMAINSKI, A.B.C. Fenologia e necessidades térmicas da videira na Serra Gaúcha. CONGRESSO BRASILEIRO DE FRUTICULTURA, 18., 2004, Florianópolis, SC. Anais... CD-ROM.

MULLINS, F.; BOUQUET, A.; WILLIAMS, L.E. Biology of the grapevine. Cambridge: University Press, 1992.

MURAKAMI, K.R.N.; CARVALHO A.J.C.; CEREJA, B.S.; BARROS, J.C.S.M.; MARINHO, C.S. Caracterização fenológica da videira cv. Itália (Vitis vinifera L.) sob diferentes épocas de poda na região norte do Estado do Rio de Janeiro. Revista Brasileira de Fruticultura, Jaboticabal, v.24, n.3, p.615-617, 2002.

MURISIER, F.; ZIEGLER, R. Effects de la charge en bourgeons et de la densité de plantation sur le potentiel de production, sur la qualité du raisin et sur le développement végétatif. Revue Suisse de Viticulture, Arboriculture et Horticulture, Nyon, v.23, p.277-282, 1991.

NUZZO, V.; MATTHEWS, M.A. Response of fruit growth and ripening to crop level in dry-farmed cabernet sauvignon on four rootstocks. American Journal of Enology and Viticulture, Davis, v. 57, n.3, p. 314-324, 2006.

PALLIOTTI, A.; CARTECHINI, A. Cluster thinning effects on yield and grape composition in different grapevine cultivars. Acta Horticulturae, The Hague, n.512, p.111-119, 2000 .
RIBÉREAU-GAYON, J.; PEYNAUD, É.; RIBÉREAU-GAYON, P.; SUDRAUD, P. Carattere dei vini, Maturazione dell'uva, Lieviti e batteri: trattato di scienza e tecnica enologica. Brescia: AEB, 1986. v. 2.

RIZZON, L.A.; MIÉLE, A. Avaliação da cv. Cabernet Sauvignon para elaboração de vinho tinto. Ciências e Tecnologia de Alimentos, Campinas, v.22, n.2, p.192-198, 2002.

RIZZON, L.A.; ZANUZ, M.C.; MIÉLE, A. Evolução da acidez durante a vinificação de uvas tintas de três regiões vitícolas do Rio Grande do Sul. Ciências e Tecnologia de Alimentos, Campinas, v.18, n.2, p.179-183, 1998.

ROBERTO, S.R.; SATO, A.J.; BRENNER, E.A.; JUBILEU, B.S.; SANTOS, C.E.; GENTA, W. Caracterização da fenologia e exigência térmica (graus-dias) para a uva 'Cabernet Sauvignon' em zona subtropical. Acta Scientiarum, Maringá, v.27, n.1, p.183-187, 2005.

ROSIER, J. P. Novas regiões: vinhos de altitude no Sul do Brasil. In: CONGRESSO BRASILEIRO DE VITICULTURA E ENOLOGIA, 10., 2003, Bento Gonçalves. Anais... Bento Gonçalves: Embrapa Uva e Vinho, 2003. p.137-140.

SANTOS, C.E.; ROBERTO, S.R.; SATO, A. J.; JUBILEU, B. S. Caracterização da fenologia e da demanda térmica das videiras 'Cabernet Sauvignon' e 'Tannat' para a região norte do Paraná. Acta Scientiarum, Maringá, v.29, n.3, p.361-366, 2007.

SILVA, L. C.; KRETZSCHMAR, A.A.; RUFATO, L.; BRIGHENTI, A.F.; SCHLEMPER, C. Níveis de produção em vinhedos de altitude da cv. Malbec e seus efeitos sobre os compostos fenólicos. Revista Brasileira de Fruticultura, Jaboticabal, v.30, n.3, p.675-680, 2008.

SOUSA, J. S. I. Uvas para o Brasil. 2. ed. Piracicaba: FEALQ, 1996.

SOUZA, C.M.; REGINA, M.A.; PEREIRA, G.E.; FREITAS, G.F. Indicação de cultivares de videira para o sul de Minas Gerais. In: REGINA, M. A. et al. (Ed.). Viticultura e enologia: atualizando conceitos. Andradas: Epamig-CECD, 2002. p.277-286.

WYLER, P.; SILVA, F.E.C.; SANTOS, J.O.; ALVES, L.A.; SOARES, J.M.; GUERRA, C.C.; LIRA, M.M.P.; PEREIRA, G.E. Avaliação das características enológicas da cv. Alicante Bouschet produzida em uma região tropical, no Nordeste do Brasil. In: CONGRESSO LATINO-AMERICANO DE VITICULTURA E ENOLOGIA, 11., 2007, Mendoza. Anais... Mendoza: Instituto Nacional de Vitivinicultura, 2007. CD-ROM. 